\title{
Genetic diversity of breeding popcorn lines determined by SSR markers
}

\author{
Ana Paula Ribeiro Trindade \\ Department of Agronomy \\ Universidade Estadual de Maringá \\ Av. Colombo, 5790, CEP 87020900 \\ Maringá, PR, Brazil \\ Ronald José Barth Pinto \\ Department of Agronomy \\ Universidade Estadual de Maringá \\ Av. Colombo, 5790, CEP 87020900 \\ Maringá, PR, Brazil \\ Antonio Teixeira do Amaral Júnior \\ Laboratório de Melhoramento Genético Vegetal \\ Universidade Estadual do Norte Fluminense Darcy Ribeiro \\ Av. Alberto Lamego, 2000, Parque Califórnia, CEP 28013602 \\ Campos dos Goytacazes, RJ, Brazil \\ Claudete Aparecida Mangolin \\ Department of Cellular Biology and Genetic \\ Universidade Estadual de Maringá \\ Av. Colombo, 5790, CEP 87020900 \\ Maringá, PR, Brazil \\ Maria de Fátima Pires da Silva Machado \\ Department of Cellular Biology and Genetic \\ Universidade Estadual de Maringá \\ Av. Colombo, 5790, CEP 87020900 \\ Maringá, PR, Brazil \\ Carlos Alberto Scapim* \\ Department of Agronomy \\ Universidade Estadual de Maringá \\ Av. Colombo, 5790, CEP 87020900 \\ Maringá, PR, Brazil \\ E-mail: cascapim@uem.br
}

Financial support: National Counsel of Technological and Scientific Development (CNPq), Coordination for the Improvement of Higher Education Personnel (CAPES), and Fundação Araucária - Foundation in Support of the Scientific and Technological Development of the State of Paraná, Brazil.

Keywords: advanced generations, genetic variability, molecular markers, Zea mays.

Abbreviations: PCR: polymerase chain reaction

SSR: simple sequence repeats

UPGMA: Unweighted Pair-Group Method Using Arithmetic Averages

Information about genetic dissimilarity is very important to corroborate genealogical relationships and to predict the most heterozygotic hybrid combinations. Eight popcorn $S_{6}$ lines of diverse germplasm types were evaluated using simple sequence repeats (SSR) markers. Of a total of 51 evaluated polymorphic primers, 15 were used for polymerase chain reaction (PCR) amplification. The genetic distance was estimated by Rogers' modified distance. The different popcorn breeding programs in Brazil are possibly using highly similar base-populations. The genetic similarity of lines

*Corresponding author
P1-3 and P8-1 was lowest, while P3-3 and P8-2 were genetically more similar. The cophenetic correlation showed that the Unweighted Pair-Group Method Using Arithmetic Averages (UPGMA) was reliable to discriminate the genotypes in five groups. The clusters were consistent with the estimates of genetic identity. There was a moderate coincidence degree between the groups and genealogy of lines. Higher levels of heterozygosity are expected from crosses between the group containing lines P3-3 and P7-3 with that of P1-3 and P7-4. Crosses between lines P1-3 and P8-1 are also promising. 


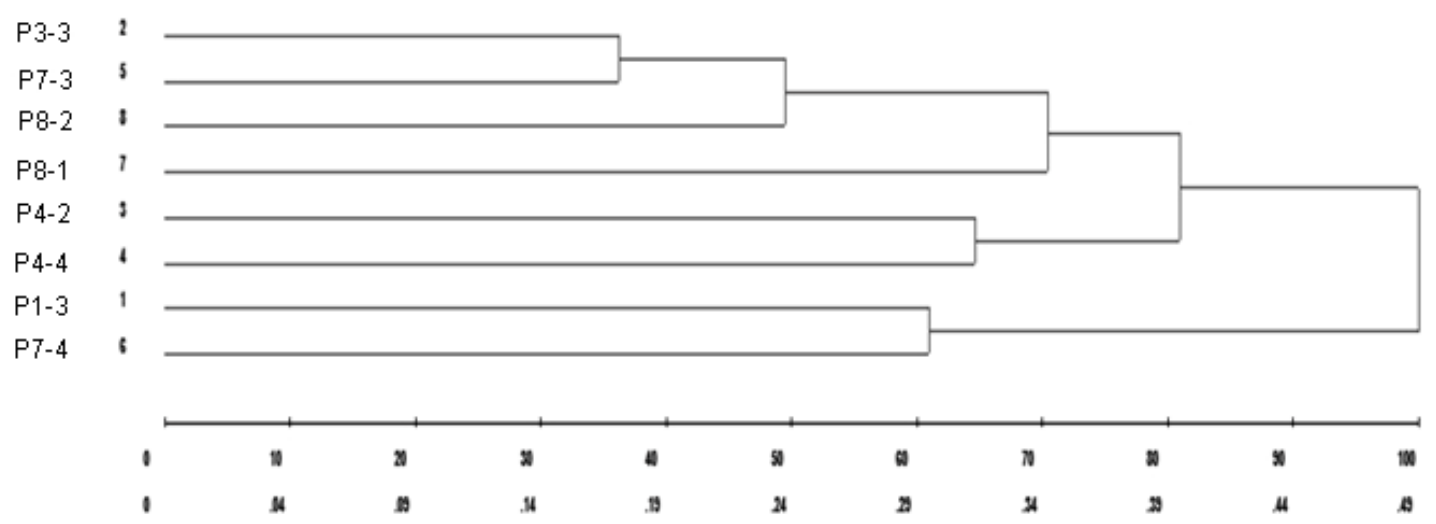

Figure 1. UPGMA dendrogram obtained for the eight $S_{6}$ popcorn inbred lines based on 10 SSR markers data.

Popcorn germplasm has a narrow genetic base (Ziegler, 2000), possibly as consequence of use of a relatively small number of popcorn lines developed from flint corn germplasm, modified by selection to maximize popping expansion and quality (Kantety et al. 1995).

A narrow genetic base is undesirable for popcorn breeding because a certain level of parental divergence is needed to create productive hybrids. In maize, a broad genetic base is desirable and associated with the improvement of both open pollinated cultivars and heterotic hybrids (Hallauer and Miranda Filho, 1988).

Selection has led to better popcorn grain quality over time. On the other hand, stalks have become more sensitive to breaking and lodging, and plants have become more susceptible to diseases than the common form of Zea mays (Arnholdt et al. 2007; Silva et al. 2007). Moreover, the genetic development of popcorn required the evaluation of lines from different genetic backgrounds in an attempt to rescue heterosis for grain yield without quality loss (Viana and Matta, 2003; Daros et al. 2004; Freitas Júnior et al. 2006; Silva et al. 2007). This situation is more serious in view of the possibility that some of the genotypes grown by farmers may have been derived from germplasm groups with a high genetic relationship.

Studies relating popping expansion and grain yield are of fundamental importance in Brazil, because the heterosis and genetic variability for popping expansion are low in Brazilian popcorn populations, especially when compared to imported commercial cultivars (Miranda et al. 2008).

Table 1. General features of the eight $S_{6}$ popcorn lines evaluated in Maringá-PR, Brazil.

\begin{tabular}{|c|c|c|c|}
\hline Line & Pedigree & Climatic adaptation & Developer \\
\hline P1-3 & Three-way hybrid Zelia & Temperate/tropical & Pioneer Hi-bred \\
\hline P3-3 & Open-pollinated variety CMS 42 & Tropical & $\begin{array}{c}\text { Maize and Sorghum National Research } \\
\text { Center (Embrapa) }\end{array}$ \\
\hline P4-2 & Composite CMS 43 & Tropical & $\begin{array}{c}\text { Maize and Sorghum National Research } \\
\text { Center (Embrapa) }\end{array}$ \\
\hline P4-4 & Composite CMS 43 & Tropical & Maize and Sorghum National Research \\
Center (Embrapa)
\end{tabular}


Table 2. Basic information about the different SSR primers used to estimate the genetic distances between eight $\mathrm{S}_{6}$ popcorn lines in Maringá-PR, Brazil.

\begin{tabular}{|c|c|c|c|}
\hline Locus & Nucleotide Sequences & Number of & Chromosome \\
\hline umc 1241 & TGACACACCCATACTTCCAACAAG (Reverse) & 3 & 7 \\
\hline umc 1241 & TGAAGCAAGTCACTGGTAAGAGCA (Forward) & & \\
\hline umc 1336 & СTCTGTTTTGGAAGAAGCTTTTGG (Reverse) & 2 & 10 \\
\hline umc 1336 & GTACAAATGATAAGCAAGGGGCAG (Forward) & & \\
\hline umc 1422 & CTCATCGCGATCTCCCAGTC (Reverse) & 3 & 2 \\
\hline umc 1422 & GAGATAAGCTTCGCCCTGTACCTC (Forward) & & \\
\hline umc 1495 & TACTGATGGGGGAACGAATAATTG (Reverse) & 3 & 3 \\
\hline umc 1495 & ACACAGCACAACACAACACAACAC (Forward) & & \\
\hline umc 1636 & GTACTGGTACAGGTCGTCGCTCTT (Reverse) & 4 & 9 \\
\hline umc 1636 & GTACTGGTACAGGTCGTCGCTCTT (Reverse) & & \\
\hline umc 1656 & GTACGAGCAGGCCATTAACCC (Reverse) & 4 & 6 \\
\hline umc 1656 & AGTTTTGACCGCGCAAAAGTTA (Forward) & & \\
\hline umc 2227 & AGCTGAGCCTTCTCTTCTTGGCT (Reverse) & 4 & 1 \\
\hline umc 2227 & ACCTTGAGCGTGGAGTCGGT (Forward) & & \\
\hline umc 2245 & CGTCGTCTTCGACATGTACTTCAC (Reverse) & 3 & 2 \\
\hline umc 2245 & GCCCTGTTATTGGAACAGTTTACG (Forward) & & \\
\hline umc 2255 & CTGCTGAGGAGAAGTGATCCTGTT (Reverse) & 3 & 3 \\
\hline umc 2255 & GCTACGCTTAAGTATCACGGCAAC (Forward) & & \\
\hline umc 2262 & CGTTCCCTGGTACCCTGTCTATAA (Reverse) & 4 & 3 \\
\hline umc 2262 & TCTGTTCGGGATTCTTCTTCAGTC (Forward) & & \\
\hline umc 2292 & ACTTCCGGCATGTCTTGTGTTT (Reverse) & 3 & 5 \\
\hline umc 2292 & AGCAGAAGAGGACAAACCAGATTC (Forward) & & \\
\hline umc 2302 & CTATACAGCCCTCAGCTCTGCTGT (Reverse) & 2 & 5 \\
\hline umc 2302 & GCATATGCGAGATCATATCGTTGA (Forward) & & \\
\hline umc 2312 & АССССАТСTCAGTCTCАСТСАСТT (Reverse) & 2 & 6 \\
\hline umc 2312 & GCTGATGAGCTCGCCATTCT (Forward) & & \\
\hline umc 2319 & GATCCACGCGAGGTTCACTG (Reverse) & 2 & 6 \\
\hline umc 2319 & GCTCTCACTAGCCTCGCATTCC (Forward) & & \\
\hline umc 2343 & GACTGACAACTCAGATTTCACCCA (Reverse) & 3 & 9 \\
\hline umc 2343 & TCATСТTССССАСАAАТTTTСАТT (Forward) & & \\
\hline
\end{tabular}

Besides, sales in the Brazilian popcorn market reach billions of dollars annually, primarily due to the use of North American hybrids registered in Brazil and used by packaging companies, e.g., P608, P608 HT, P618, P621 and P625 (Freitas Junior et al. 2006). This is one reason why only three hybrids developed in partnership between public and private institutions in Brazil were released in the growing season 2005/2006: IAC 112 (single modified hybrid - Agronomic Institute of Campinas), Zélia (three- way hybrid - Pioneer) and Jade (three-way hybrid Pioneer).

One of the first steps to obtain superior hybrids is the identification of divergent parents (Cruz et al. 2004). This procedure has provided more reliable results when molecular markers are used because small divergence among lines is not discriminated by conventional methods. Thus, molecular markers can be very useful to identify 
heterotic groups of genotypes as a consequence of the different allele frequencies of populations (Barata and Carena, 2006; Solano Solis et al. 2007; Balestre et al. 2008; Legesse et al. 2008).

Among several kinds of molecular markers, simple sequence repeats (SSR) markers have the advantage of being multiallelic, highly polymorphic, co-dominant and highly reproducible, providing rich genetic information in situ (Balestre et al. 2008; Dandolini et al. 2008).

Patterns of genetic variability in temperate and tropical popcorn germplasm have been studied by using morphologic and molecular data (Miranda et al. 2008). However, studies on the genetic diversity of popcorn germplasm are rare (Kantety et al. 1995; Miranda et al. 2008; Pereira et al. 2008). Popcorn breeding is still more difficult when breeders do not know the origin of some materials, a situation that takes place, for example, when seeds of land races are supplied by farmers. Thus the genetics of popcorn breeding might progress if more genealogical data and detailed information on popcorn genetic dissimilarity were available.

The purpose of this study was to characterize the genetic profile of eight $S_{6}$ popcorn lines from parents with different genetic constitutions, based on SSR markers, in order to obtain information about genetic dissimilarity hat corroborates genealogical relationships and to predict heterozygotic hybrid combinations in the popcorn breeding program carried out by the Maringa State University at MARINGÁ, State of Paraná, Brazil.

\section{MATERIALS AND METHODS}

Eight popcorn lines of different genetic constitutions were used in the $\mathrm{S}_{6}$ generation (Table 1).

For the DNA extraction, a $300 \mathrm{mg}$ tissue sample was used, taken from 3 leaves of each of 10 plants of each popcorn progeny, based on a method described by Hoisington et al. (1994). The extracted DNA was quantified in a fluorometer and diluted to $10 \mathrm{ng} \mu \mathrm{L}^{-1}$.

In order to select the polymorphic microsatellites for genotyping the popcorn lines, 51 pre-mapped microsatellite primers previously identified in several corn varieties and listed in the website MAIZEGDB were analyzed. The SSR reactions were prepared with a final volume of $20 \mu \mathrm{L}$ containing: $25 \mathrm{ng}$ genomic DNA, $2.0 \mu \mathrm{L}$ reaction buffer (20 $\mathrm{mM}$ Tris-HCl, pH 8.0, $0.1 \mathrm{mM}$ EDTA, $1.0 \mathrm{mM}$ DTT, 50\% (v/v) glycerol), $2.0 \mathrm{mM} \mathrm{MgCl}_{2}, 0.1 \mathrm{mM}$ of each dNTPs, 1.0 unit Taq DNA polymerase (Invitrogen), $0.2 \mu \mathrm{M}$ of each primer (forward and reverse) and milli-Q water to a volume of $20 \mu \mathrm{L}$. The amplifications were carried out in $0.2-\mathrm{mL}$ microtubes using personal Techne TC-512 Thermocycler. The amplifications were performed using Touchdown polymerase chain reaction (PCR) (Don et al. 1991). The amplified samples were fractionated in $4 \%$ agarose gel (50\% agarose and 50\% agarose MS-8) in TBE buffer X 0.5 (44.5 mM Tris, $44.5 \mathrm{mM}$ boric acid and $1 \mathrm{mM}$ EDTA), at $3.2 \mathrm{~V} / \mathrm{cm}$ for $4 \mathrm{hrs}$. To estimate the amplification fragment size, we used a 100 bp molecular weight marker (Invitrogen). The gels were then stained with ethidium bromide (0.5 $\mu \mathrm{g} \mathrm{mL}^{-1}$ ) for $40 \mathrm{~min}$, visualized under ultraviolet light and photographed by a digital camera (EDAS 290, Kodak Digital Science).

A binary matrix was constructed from the SSR results, and the genetic distances were calculated according to Rogers' modified distance (Rogers, 1972; Mohammadi and Prasanna, 2003; Cruz et al. 2004; Reif et al. 2005), using software GENES (Cruz, 2006).

The software GENES (Cruz, 2006) was used to calculate the distances and to run three hierarchical grouping methods: simple linkage or nearest neighbour, complete linkage or furthest neighbour and mean distances

Table 3. Modified Rogers' genetic distances between eight $S_{6}$ popcorn lines based on 15 SSR markers data.

\begin{tabular}{|l|l|l|l|l|l|l|l|}
\hline \multicolumn{1}{|c|}{ Lines } & P3-3 & \multicolumn{1}{|c|}{ P4-2 } & P4-4 & P7-3 & P7-4 & P8-1 & P8-2 \\
\hline P1-3 & 0.4853 & 0.6185 & 0.4706 & 0.4009 & 0.4090 & 0.6683 & 0.4447 \\
\hline P3-3 & & 0.3725 & 0.4164 & 0.3790 & 0.4824 & 0.3817 & 0.3085 \\
\hline P4-2 & & & 0.3992 & 0.5401 & 0.5599 & 0.4159 & 0.5194 \\
\hline P4-4 & & & & 0.4751 & 0.3402 & 0.5214 & 0.4331 \\
\hline P7-3 & & & & & 0.4771 & 0.4348 & 0.3229 \\
\hline P7-4 & & & & & & 0.5307 & 0.3532 \\
\hline P8-1 & & & & & & & 0.4672 \\
\hline
\end{tabular}


Table 4. Tocher grouping based on the modified Rogers' distances between eight $\mathrm{S}_{6}$ popcorn lines by using 15 SSR markers.

\begin{tabular}{|l|c|l|l|}
\hline \multicolumn{2}{|c|}{ Group formation } & \multicolumn{1}{c|}{ Genetic distances between groups } \\
\hline Group & Lines & \multicolumn{1}{c|}{ Distance } \\
\hline I & P3-3, P7-3 and P8-2 & I $\times$ II & 0.4396 \\
\hline II & P4-4 and P7-4 & I $\times$ III & 0.4436 \\
\hline III & P1-3 & I $\times$ IV & 0.4773 \\
\hline IV & P4-2 & I $\times$ V & 0.4279 \\
\hline V & P8-1 & II $\times$ III & 0.4398 \\
\hline & & II $\times$ IV & 0.4796 \\
\hline & & II $\times$ V & 0.5260 \\
\hline & & III $\times$ IV & 0.6185 \\
\hline & & III $\times$ V & 0.6683 \\
\hline & & IV $\times$ V & 0.4159 \\
\hline
\end{tabular}

(Unweighted Pair-Group Method Using Arithmetic Averages (UPGMA)). Dias (1998) described in detail the calculations required for the methods mentioned above. Estimates of cophenetic correlation coefficients were used to compare the efficiency of the grouping methods (Rohlf and Sokal, 1981; Mohammadi and Prasanna, 2003; Cruz et al. 2004; Reif et al. 2005). The significance of the relations between matrices was tested by t-test in GENES (Cruz, 2006).

For greater efficiency of the analysis, the genotypes were also grouped according to Tocher's optimization method (Rao, 1952; Cruz et al. 2004), which can be used as an alternative to the cluster analysis performed to quantify the genetic divergence, being especially useful to determine the best cut-off line in dendrograms.

In this work, an UPGMA dendrogram was constructed by GENES to indicate relationships among the genotypes analyzed.

\section{RESULTS AND DISCUSSION}

Of the 51 primer pairs that were evaluated, 17 were found to be polymorphic. Later, 2 pairs (umc1702 and umc1766) were excluded due to the low amplification resolution, i.e. 15 polymorphic primer pairs were used to determine the genetic variability in the eight $S_{6}$ popcorn lines.

The number of alleles per locus in the lines ranged from 1 to 4 , for a total of 45 alleles. The highest number of alleles was observed in loci umc2227, umc2262, umc1656, and umc1636 (Table 2).

Rogers' matrix distance (Table 3) indicated the lowest genetic identity between lines P1-3 and P8-1 (0.6683), while P3-3 and P8-2 were most similar (0.3085). It is therefore expected that the cross between P1-3 and P8-1 may be more heterozygous than others, though this result is insufficient to secure a high heterotic potential. P1-3 is derived from the three-way hybrid Zélia, adapted to both temperate and tropical climates, while P8-1 was obtained from the single hybrid Zaeli, adapted to a temperate climate. This confirms that climate adaptation and parental background are relevant factors for the differentiation of the genetic structure of lines.

The Tocher method separated the lines in five groups (Table 4). These clusters are consistent with the estimates of genetic identity, as shown by Rogers' matrix, since lines with higher identities were in the same group, as in the case of P3-3 and P8-2, forming group I, while the less similar lines, such as P1-3 and P8-1, were allocated to different groups, in this case to groups III and IV, respectively.

The greatest mean intergroup distance was observed between groups III and V, with lines P1-3 and P8-1, respectively. This supports the proposal to extend the genetic base through the combination P1-3 x P8-1. Moreover, the combination P1-3 x P4-2, where the second greatest genetic intergroup dissimilarity was detected, should not be discarded, since these are advanced 
Table 5. Modified Rogers' genetic distances between eight $S_{6}$ popcorn lines based on 10 SSR markers data.

\begin{tabular}{|l|l|l|l|l|l|l|l|}
\hline \multicolumn{1}{|c|}{ Lines } & \multicolumn{1}{c|}{ P3-3 } & \multicolumn{1}{c|}{ P4-2 } & P4-4 & P7-3 & P7-4 & P8-1 & P8-2 \\
\hline P1-3 & 0.5357 & 0.6420 & 0.3919 & 0.3724 & 0.3045 & 0.6045 & 0.5194 \\
\hline P3-3 & & 0.3063 & 0.3507 & 0.1813 & 0.5005 & 0.2618 & 0.2435 \\
\hline P4-2 & & & 0.3229 & 0.4875 & 0.5332 & 0.3375 & 0.4436 \\
\hline P4-4 & & & & 0.4069 & 0.3721 & 0.4569 & 0.4457 \\
\hline P7-3 & & & & & 0.5000 & 0.4125 & 0.2513 \\
\hline P7-4 & & & & & & 0.5750 & 0.4454 \\
\hline P8-1 & & & & & & & 0.3813 \\
\hline
\end{tabular}

generations from divergent parents; P1-3 is derived from the three-way hybrid Zélia, while P4-2 stems from the composite CMS 43, a tropically adapted, open-pollinated variety from the Maize and Sorghum National Research Center (Embrapa, Brazil).

The clustering of lines P3-3, P7-3 and P8-2 in group I, as well as P4-4 and P7-4 in group II, was unexpected, since these are advanced generations from divergent parents. A more detailed examination, however, shows that all lines but P8-2 derived from the single hybrid Zaeli were either derived from composite CMS or from population UEM. Specifically, P3-3 and P7-3 originated from composite CMS-42 and the population UEM-C2, and P4-4 and P7-4 from composite CMS-43 and population UEM-C2, respectively. This shows a trend of advanced generations of composite CMS and population UEM grouping together, which leads us to believe that their gene sets are similar. In fact, both CMS-43 and UEM-C2 are tropically adapted, open-pollinated populations with white grains. Considering that cultivar BRS ANGELA was synthesized after two cycles of intrapopulational recurrent selection applied to the population CMS-43, released in 1998 on the Brazilian market, and also that UEM-C2 is the second cycle of intrapopulational recurrent selection among and within families of half-sibs of the UEM population (Miranda et al. 2008), it is possible that different popcorn breeding programs in Brazil share the same genotypes. In any case, Miranda et al. (2008) and Dandolini et al. (2008) understand that the genetic variability among Brazilian popcorn populations allows the exploitation of additive and non-additive effects for grain yield by using local varieties, though Miranda et al. (2008) consider the attainment of commercial hybrids from local varieties whose popping expansion is poor to be difficult.

These observations indicate the need for further research on the genetic variability of improved populations and local popcorn races in Brazil, for a clear understanding of the genetic basis of the germplasm that is used in breeding programs, or can be included in such programs, to select genotypes not only for higher expansion volume but also for grain yield and pest and disease resistance, including ears with better husk coverage and plants with greater breaking and lodging tolerance.

In China, Li et al. (2004) evaluated the genetic diversity of 56 popcorn lines representing a broad sample of the crop, plus 21 lines of common maize from different heterotic groups of local breeding programs. The authors found differentiating groups between popcorn and common maize lines, and identified seven heterotic groups whose formation was highly concordant with earlier improvement studies. They emphasized the importance of using SSR markers in studies of genetic divergence in popcorn and common maize lines.

Santacruz-Varela et al. (2004) used 29 morphological markers, 18 isoenzymatic loci and 31 SSR loci to assess the relationship among popcorn germplasms representing the Americas. The study included 56 populations from the USA and nine from Latin American countries, which were clustered by grouping analysis and principal components. The recognition of three groups was proposed for the clustering of genotypes, namely: i) "Yellow Pearl Popcorn", which represents the largest trade group from the USA; ii) "North American Pointed Rice Popcorns", which probably originated from a complex of traditional popcorn races from Latin America; and iii) "North American Early Popcorns", which are closely related with the "flint" common maize types in the northern USA.

In Brazil, there is only one report about the use of SSR markers in the identification of genetic variability of popcorn germplasm (Dandolini et al. 2008). The scarcity of studies involved, and of traditional breeding programs, is an obstacle to the development of superior hybrids for most 
Table 6. Tocher grouping based on the modified Rogers' distances between eight $\mathrm{S}_{6}$ popcorn lines by using 10 SSR markers data.

\begin{tabular}{|l|c|c|c|}
\hline \multicolumn{2}{|c|}{ Group formation } & \multicolumn{2}{c|}{ Genetic distances between groups } \\
\hline \multicolumn{1}{|c|}{ Group } & Progenies & Group & Distance \\
\hline \hline I & P3-3, P7-3 and P8-2 & I x II & 0.4789 \\
\hline II & P4-2 and P4-4 & I x III & 0.4881 \\
\hline III & P8-1 & I x IV & 0.3519 \\
\hline IV & P1-3 and P7-4 & II x III & 0.4848 \\
\hline & & II x IV & 0.5896 \\
\hline \hline & & III x IV & 0.3972 \\
\hline
\end{tabular}

productive areas of the country. This situation is largely the same in South America, Africa and Oceania.

Liu et al. (2003) estimated the genetic relationship among 260 corn inbred lines, identifying a consensus genotype for each popcorn progeny. In their studies, the inclusion of small numbers of sweet and popcorn lines prevented convergence to a robust solution. In some cases, the authors detected levels of heterozygosity up to 0.20 , considered very high for pure lines. In our work, we also had problems in the identification of some consensus genotypes because some variation within lines was observed. This variation might be a consequence of the very small heterozygosis remaining in the $\mathrm{S}_{6}$ lines, or even a product of contamination in the field. Careful study of the results showed an abnormal pattern of bands (suggesting an unexpected heterozygosis), in all samples, whenever five specific primers were used (umc1636, umc2262, umc2292, umc1656, and umc2227). Since the hypothesis of contamination was rejected, the removal of these five primers became necessary to allow more accurate analysis of the bands and identify all popcorn genotypes. The distances were estimated again by Rogers' genetic algorithm (Table 5).

The genetic similarity was lowest between lines P1-3 and P4-2 and highest between P3-3 and P7-3, as shown by the distance estimates of 0.6420 and 0.1813 . Again the similarity of CMS and UEM was clear, since lines derived from CMS-42 and UEM-C2 were genetically most similar. These results support the premise of the similarity of genotypes under recurrent selection in the different popcorn breeding programs in Brazil.

The new grouping by the Tocher method (Table 6) led to the formation of four groups, where group I is coincident with the analogous group formed based on 15 SSR primers
(Table 4). Another similarity was the isolation of line P8-1 in a single group.

An analysis without the information produced from some primers grouped lines P4-2 and P4-4, previously assigned to separate groups, as well as lines P1-3 and P7-4. For the first grouping, it is believed that segregation of common allelic genealogy favoured genetic similarities and allowed the joining of lines more compatible with the parents. In turn, the joint grouping of P1-3 and P7-4 cannot be explained by the genetic constitution of the genealogies. A remote or even near, although unknown, common ancestor is presumed for these genealogies, favouring the emergence of lines with close genomes. On the other hand, the divergent characteristics of P1-3 and P7-4 allow one to suppose that the cross between them may increase heterozygosis and enlarge the genetic base of our program (Table 1).

The association of genotypes based on less polymorphic primers explains why the highest distance value between the Tocher groupings (magnitude 0.5896, as shown in Table 6) was lower when all 15 primers were used, for which the greatest discrepancy between groups was expressed by the distance estimate of 0.6683 (Table 4).

The selection of primers did not substantially increase the coincidence degree between the groups and genealogy of lines. This was confirmed by the allocation of progenies by the UPGMA method (Figure 1), which formed four groups: Group I, containing progenies P3-3, P7-3 and P8-2; Group II, with P1-3 and P7-4; Group III, with P4-2 and P4-4; and Group IV, with the advanced generation P8-1. These results are consistent with those obtained by the Tocher algorithm for the same 10 SSR primers (Table 6).

The cophenetic correlation coefficients for each clustering method pointed to UPGMA as the most appropriate method 
to explain the varietal discrimination. The correlation coefficient between the matrix of cophenetic Rogers' genetic distances and the matrix of cophenetic distances between lines in the UPGMA dendrogram was estimated at 0.6009 , which was highly significant at $1 \%$ probability by the t-test, confirming the reliability of the groups based on the UPGMA algorithm.

Comparisons between the Tocher groups, based on 10 as well as 15 polymorphic primers, and the group formation by UPGMA algorithm allow inferences about the consistency of the association of lines P3-3, P7-3 and P8-2, since these lines were clustered together in all grouping procedures. In this aspect, the segregation caused by inbreeding probably favoured the association of genetically similar descendants derived from an unknown and remote common ancestor.

Although our results cannot be used to identify heterotic groups, a great difference between groups was systematically observed in all analyses of genetic dissimilarity between clusters containing P1-3 and P8-1.

\section{REFERENCES}

ARNHOLDT, Emmanuel; SILVA, Derly José H.; MELLO FILHO, Odilon L. and VIANA, José Marcelo S. Inbreeding depression simulation in popcorn cultivars to estimate the effective population size for germplasm conservation. Crop Breeding and Applied Biotechnology, March 2007, vol. 7, no. 1, p. 321-326.

BALESTRE, M.; MACHADO, J.C.; LIMA, J.L.; SOUZA, J.C. and NÓBREGA-FILHO, L. Genetic distance estimates among single cross hybrids and correlation with specific combining ability and yield in corn double cross hybrids. Genetics and Molecular Research, January 2008, vol. 7, no. 1, p. 65-73.

BARATA, C. and CARENA, M.J. Classification of North Dakota maize inbred lines into heterotic groups based on molecular and testcross data. Euphytica, March 2006, vol. 151, no. 3, p. 339-349.

CRUZ, Cosme D.; REGAZZI, Adair J. and CARNEIRO, Pedro Crescêncio S. Modelos biométricos aplicados ao melhoramento genético. Viçosa; Editora UFV, 2004. 480 p. ISBN 85-7269-023-9.

CRUZ, Cosme D. Programa GENES: análise multivariada e simulação. Viçosa; Editora UFV, 2006. 175 p. ISBN 857269-248-7.

DANDOLINI, Thatiana S.; SCAPIM, Carlos A.; AMARAL JÚNIOR, Antonio T.; MANGOLIN, Claudete A.; MACHADO, Maria de Fátima Pires S.; MOTT, Andressa S. and LOPES, Ana D. Genetic divergence in popcorn lines detected by microsatellite markers. Crop Breeding and Applied Biotechnology, October 2008, vol. 8, no. 4, p. 313-320.
DAROS, Máskio; AMARAL JÚNIOR, Antonio T.; PEREIRA, Messias G.; SANTOS, Fabrício S.; GABRIEL, Ana Paula C.; SCAPIM, Carlos A.; FREITAS JÚNIOR, Silvério de P. and SILVÉRIO, Lucas. Recurrent selection in inbred popcorn families. Scientia Agricola, December 2004, vol. 61, no. 6, p. 609-614.

DIAS, L.A.S. Análises multidimensionais. In: ALFENAS, A.C. ed. Eletroforese de isoenzimas e proteínas afins. Viçosa, Editora UFV, 1998, p. 405-475.

DON, R.H.; COX, P.T.; WAINWRIGHT, B.J.; BAKER, K. and MATTICK, J.S. 'Touchdown' PCR to circumvent spurious priming during gene amplification. Nucleic Acids Research, July 1991, vol. 19, no. 14, p. 4008.

FREITAS JÚNIOR, Silvério de P.; AMARAL JÚNIOR, Antonio T.; PEREIRA, Messias G.; CRUZ, Cosme D. and SCAPIM, Carlos A. Combining ability in popcorn by circulant diallel. Pesquisa Agropecuária Brasileira, November 2006, vol. 41, no. 11, p. 1599-1607.

HALLAUER, A.R. and MIRANDA FILHO, J.B. Quantitative genetics in maize breeding. $2^{\text {nd }}$ ed. Ames; Iowa State University Press, 1988. 468 p. ISBN 0-81381522-3.

HOISINGTON, D.; KHAIRALLAH, M. and GONZÁLEZLÉON, D. Laboratory protocols: CIMMYT applied molecular genetics laboratory. D.F. Mexico; CIMMYT Press, 1994. 50 p. ISBN 968-6923-30-6.

KANTETY, Ramesh V.; ZENG, Xiaoping; BENNETZEN, Jeffrey L. and ZEHR, Brent E. Assessment of genetic diversity in dent and popcorn (Zea mays L.) inbred lines using inter-simple sequence repeat (ISSR) amplification. Molecular Breeding, July 1995, vol. 1, no. 4, p. 365-373.

LEGESSE, B.W.; MYBURG, A.A.; PIXLEY, K.V.; TWUMASI-AFRIYIE, S. and BOTHA, A.M.Relationship between hybrid performance and AFLP based genetic distance in highland maize inbred lines. Euphytica, August 2008, vol. 162, no. 3, p. 313-323.

LI, Y.L.; LV, D.B.; WANG, Y.Z.; CHEN, S.J. and TANG, J.H. Study on the genetic diversity of popcorn inbred sang their germplasm relationship with normal corn inbreds using SSR markers. Maydica, 2004, vol. 49, p. 327-333.

LIU, Kejun; GOODMAN, Major; MUSE, Spencer; SMITH, J. Stephen; BUCKLER, Ed and DOEBLEY, John. Genetic structure and diversity among maize inbred lines as inferred from DNA microsatellites. Genetics, December 2003, vol. 165, no. 4, p. 2117-2128.

MIRANDA, Glauco V.; SOUZA, Leandro V.; GALVÃO, João Carlos C.; GUIMARÃES, Lauro J.M.; MELO, Aurélio V. and SANTOS, Izabel C. Genetic variability and heterotic groups of Brazilian popcorn populations. Euphytica, August 2008, vol. 162, no. 3, p. 431-440. 
MOHAMMADI, S.A. and PRASANNA, B.M. Analysis of genetic diversity in crop plants-salient statistical tools and considerations. Crop Science, July 2003, vol. 43, no. 4, p. 1235-1248.

PEREIRA, Liz K.; SCAPIM, Carlos A.; MANGOLIN, Claudete A.; MACHADO, Maria de Fátima P.S.; PACHECO, Cleso Antonio P. and MORA, Freddy. Heterozigosity following half-sib recurrent selection in popcorn using isoenzyme markers. Electronic Journal of Biotechnology, January 2008, vol. 11, no. 1, p. 107-115.

RAO, C. Radhakrishna. Advanced statistical methods in biometric research. New York, John Wiley, 1952. 390 p.

REIF, J.C.; MELCHONGER, A.E. and FRISH, M. Genetical and mathematical properties of similarity and dissimilarity coefficients applied in plant breeding and seed bank management. Crop Science, January-February 2005, vol. 45, no. 1, p. 1-7.

ROGERS, J.S. Measures of genetic similarity and genetic distance. In: Studies in genetics VII. Austin, University of Texas, 1972, p. 145-153.

ROHLF, F. James and SOKAL, Robert R. Comparing numerical taxonomic studies. Systematic Zoology, 1981, vol. 30, no. 4, p. 459-499.

SANTACRUZ-VARELA， A.; WIDRLECHNER, M.P.; ZIEGLER, K.E.; SALVADOR, R.J.; MILLARD, M.J. and BRETTING, P.K. Phylogenetic relationships among North American popcorns and their evolutionary links to Mexican and South American popcorns. Crop Science, July-August 2004, vol. 44, no. 4, p. 1456-1467.

SILVA, Maria Fernanda P.T.B.; LOPES, Eraldo F.; PAGLIARINI, Maria S. and SCAPIM, Carlos A. Effects of endogamy on microsporogenesis in popcorn. Crop Breeding and Applied Biotechnology, September 2007, vol. 7, no. 3, p. 321-326.

SOLANO SOLIS, Jaime; MORALES ULLOA, Daniza and ANABALÓN RODRÍGUEZ, Leonardo. Molecular description and similarity relationships among native germoplasm potatoes (Solanum tuberosum ssp. tuberosum L.) using morphological data and AFLP markers. Electronic Journal of Biotechnology, July 2007, vol. 10, no. 3, p. 436-443.

VIANA, José Marcelo S. and MATTA, Frederico P. Analysis of general and specific combining abilities of popcorn populations, including selfed parents. Genetics and Molecular Biology, December 2003, vol. 26, no. 4, p. 465471.

ZIEGLER, K.E. Popcorn. In: HALLAUER, A.R. ed. Specialty corns. $2^{\text {nd }}$ ed. Boca Raton, Florida; CRC Press, 2000, p. 199-234. 